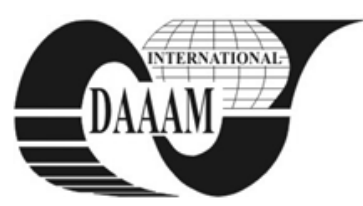

\title{
APPLICATION OF POLYMERIC IMPAK MATERIAL TO MITIGATE THE CRANIO- MANDIBULAR EFFECTS OF STRESS
}

\author{
BECHIR, A[namaria]; GHERGIC, D[oina] L[ucia]; BECHIR, E[dwin] S[ever]; SMATREA, O[ana]; \\ POPESCU, A[nca] I[uliana] \& GIOGA, C[herana]
}

\begin{abstract}
Starting from acrylic resins with improved properties than classic acrylic resins, the authors analyzed the beneficial effect of the polymeric nightguards, obtained from Impak modern resins. 53 male patients, aged between 35-39 years, performing specific activities with both high risk factor and stress, suffering from bruxism associated with pain in the cranio-mandibular area, were selected for our study. The study results have showed that the nightguards made of Impak resin have mitigated the effects of stress and have reduced the symptoms of pain in the cranio-mandibular area, but the strength and the color stability of the Impak resin nightguards was in relation to the type of curing.
\end{abstract}

Key words: stress, bruxism associated with pain, Impak resin nightguards

\section{INTRODUCTION}

Synthetic polymers constitute a distinct and dynamic class of biomaterials, and, through their diversity, represent a need in health domain (Bumann \& Lotzmann, 2002; Gebelein, 1991; Shalaby, 2006).

Patients who exercise a profession with a high risk factor (distressful climate, psychological and physical pressure, constant exposure to noise and vibration, and so), suffer the phenomenon of stress, which is manifested by fatigue, sleep and hearing disturbances, communication difficulties to community members, or even the occurance of illnesses such as bruxism, gastric and duodenal ulcers, hypertension, impaired immunity, etc. (Gerrig \& Zimbardo, 2009).

Bruxism is a stereotyped movement disorder characterized by grinding or clenching of teeth. The disorder has been identified as daytime or/and sleep bruxism and once the disorder is known, often can be modified. Sleep bruxism is a different form of daytime bruxism, it is related to stress, beyond volitional control, and probably, of different (Falace, 2007).

Nightguards are intra-oral dental appliances, interposed between the teeth of dental arches. These appliances, manufactured individually for each patient, are used in cases of painful disorders of the temporo-mandibular joint and may be made of rubber, elastomers and acrylic resins (Wright, 2009).

\section{MATERIAL AND METHOD}

IMPAK-Transparent (Vernon-Benshoff Co.) is a soft dental material, presenting a variety of features which are not found in traditional acrylic materials, but adheres to traditional acrylic polymers and this resin can be used to manufacture nightguards. The presentation of the material is a two component system, a powder and a transparent liquid.

The acrylic resin powder is solid at room temperature, and is comprised of polymethylmethacrylate, initiator, pigments, opacificator, plasticizers, and particles of organic and inorganic fibres. The particles are spherical and their coalescence was avoided by adding inert substances. Benzoylperoxide (0.5-2\% percent by weight) incorporated into the structure of polymethylmethacrylate, is a donor of free radicals during the heat curing process of acrylate paste (paste which is the result by mixing the powder with the liquid). Also, to facilitate the formation of acrylic powder pearls, a plasticizer is incorporated, plasticizer represented by a monomer with larger groups than methyl-methacrylate. Polymethyl-methacrylates are resins that can polymerize through heat. Their softening temperature is around $125^{\circ} \mathrm{C}$ and above this temperature the depolymerisation of powder occurs. The liquid of heat cured acrylic resins contain monomer (methyl metacrylate), inhibitors, plasticizers and hardening agents. The monomer is not chemically stable and tends to spontaneous polymerization under the action of light and heat, reason for which an antioxidant is added (hydroquinone, $0.006 \%$ by mass), having also an inhibitor of polymerization role, which allows fluid preservation.

Polymerization reaction is initiated at a temperature of $65^{\circ} \mathrm{C}$ in the entire mass of material. The polymerization of methyl methacrylate occurs with a strong contraction (21\%), and therefore it is mixed with polymethyl methacrylate powder. The preparation of acrylic paste consists by mixing the liquid with the powder into a bowl of glass or plastic. Initially, the mixture looks like a sandy mass, which later turns into a homogeneous mass (Shalaby, 2006).

We selected 53 male patients for our research, aged between 35 and 39, performing specific activities with a high risk factor and stress, suffering from bruxism associated with painful symptoms in the cranio-mandibular area.

In order to proceed the comparative clinical trials, patients were divided into three batches.

The first and second batch of patients received therapy with nightguards achieved of Impak-Transparent resin (VernonBenshoff $\mathrm{Co}$ ), cured under slow and fast thermal regime.

The 15 patients of the third batch represented the control group.

The nightguards were manufactured by the indirect method, after the impression of dental arches and the bite registration. The 19 nightguards of the first batch of patients were manufactured by slow polymerisation of the material ( 5 hours to $74^{\circ} \mathrm{C}$ ) and the other 19 nightguards of the second batch through fast polymerization $\left(1 \frac{1}{2}\right.$ hours at $74^{\circ} \mathrm{C}$ and boiling for 30 minutes at $100^{\circ} \mathrm{C}$ ). The nightguards were laid on the teeth of the lower dental arch, and were used during sleep, for at least 6 hours of 24 hours.
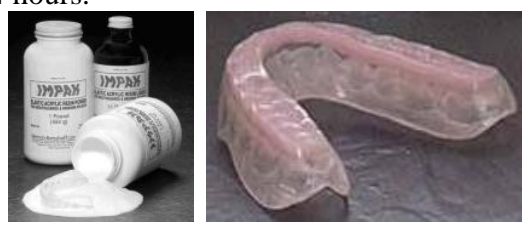

Fig. 1. The presentation of Impak Transparent resin (left) and the aspect of a manufactured nightguard (right)

\section{RESULTS AND DISCUSSION}

We performed 3 determinations, to establish the maintenance, mitigation or disappearance of painful syndrome in cranio-mandibular area. The determinations were realized 
after using the nightguards, in weeks 14,18 and 22 of treatment (after 3, 4 and 5 months). The determinations consisted of subjective assessments of patients themselves (regarding the maintenance / reduction / disappearance of bruxism and painful syndrome in oro-facial area), corroborated with the objective assessments (palpation of the perioral and cranial muscles, with regards to the contraction degree of muscular fascicles), and the results were recorded as follows:

$\mathbf{O}, \mathbf{S}=$ existence of objective simptomatology (contraction of perioral and cranian muscular fascicles) and subjective simptomatology (teeth and oro-facial pain);

$\mathbf{O}=$ existence of objective simptomatology;

$\mathbf{S}=$ existence of subjective simptomatology;

- = nonexistence of subjective and objective simptomatology.

After processing data, the final results showed that:

- In patients of the first batch, the objective and subjective symptomatology was significantly diminished in 7 cases and disappeared in 12 cases;

- In patients of the second batch, the objective and subjective symptomatology persisted in one case, was significantly diminished in 9 cases and disappeared in 9 cases;

- In patients of the control batch, the objective and subjective symptomatology persisted in all cases.

\begin{tabular}{||l||c|c||c|c|c|c||}
\hline \multirow{2}{*}{ Results } & \multicolumn{2}{c||}{$\begin{array}{c}\text { After 14 } \\
\text { weeks }\end{array}$} & \multicolumn{2}{c|}{$\begin{array}{c}\text { After 18 } \\
\text { weeks }\end{array}$} & \multicolumn{2}{c||}{$\begin{array}{c}\text { After 22 } \\
\text { weeks }\end{array}$} \\
\cline { 2 - 7 } & $\begin{array}{c}\text { 1-st } \\
\text { batch }\end{array}$ & $\begin{array}{c}\text { 2-nd } \\
\text { batch }\end{array}$ & $\begin{array}{c}\text { 1-st } \\
\text { batch }\end{array}$ & $\begin{array}{c}\text { 2-nd } \\
\text { batch }\end{array}$ & $\begin{array}{c}\text { 1-st } \\
\text { batch }\end{array}$ & $\begin{array}{c}\text { 2-nd } \\
\text { batch }\end{array}$ \\
\hline \hline Patient 1 & O & O & - & - & - & - \\
\hline Patient 2 & O,S & O,S & O & O & S & - \\
\hline Patient 3 & O,S & O,S & S & S & S & S \\
\hline Patient 4 & O,S & O,S & S & S & - & - \\
\hline Patient 5 & O & O,S & S & S & - & - \\
\hline Patient 6 & O & O & - & - & - & - \\
\hline Patient 7 & O,S & O,S & O & O & S & S \\
\hline Patient 8 & O & O,S & - & O & - & S \\
\hline Patient 9 & O,S & O,S & O & O & S & S \\
\hline Patient 10 & O & O & - & - & - & - \\
\hline Patient 11 & O & O,S & S & O,S & - & O,S \\
\hline Patient 12 & O & O & - & - & - & - \\
\hline Patient 13 & O,S & O,S & O & O & S & S \\
\hline Patient 14 & O & O,S & - & O & - & S \\
\hline Patient 15 & O,S & O,S & O & O & S & S \\
\hline Patient 16 & O & O & - & - & - & - \\
\hline Patient 17 & O & O & - & O & - & S \\
\hline Patient 18 & O & O,S & O & O & S & S \\
\hline Patient 19 & O,S & O & - & - & - & - \\
\hline
\end{tabular}

Table 1. The obtained results in the patients with treatment with Impak resin nightguards (first and second batch of patients)

After processing data, we observed that after 3 months of therapy with Impak resin nightguards, the bruxism and the painful symptomatology, in both batches of treated patients, persisted in one case, decreased significantly in 16 cases and disappeared in 21 cases.After a 3 month use, we observed that the colors of Impak nightguards were different: the slowly heatcured appliances presented same shade of color, but the fast heat-cured appliances presented an opaque shade of colour.

The mechanical resistance was reduced in fast heat-cured Impak nightguards, compared to the slowly heat-cured nightguards, and at end of study we remarked that in three fast cured nightguards fissures occurred, probably caused by the phenomenon of resin "ageing".

Impak polymeric material is prepared and processed by using similar procedures to those used for conventional heat cured acrylic dentures and it bonds to traditional acrylics. It is rigid when cold and soft at intraoral temperatures, so appliances have the advantages over those made with traditional acrylics, such as greater patient comfort. Decreasing the powder / liquid ratio results a softer appliance and increasing the powder/ liquid ratio results a stiffer appliance. The technique for curing the Impak resin paste is in a mould, in bath of warm water, under pressure.

If the curing temperature is raised suddenly, a variety of polymerization centers will appears, with the formation of many short-chain polymers that will determine a structure with a high degree of hardening, which leads to low hardness of the final polymer. Slower polymerizations produce the formation of a smaller number of chains, which have a much higher molecular weight. Thus, progressively increasing the paste viscosity, easier access of the monomer and hardening agent is provided, which will lead to the formation of chains and reticular structures. The presence of large amounts of residual monomer and unpolymerized hardening agent, through their plasticizing action, will cause unfavorable mechanical properties and optical qualities of the Impak resin nightguards.

In future, we will perform comparative researches regarding the efficiency and effectiveness of nightguards used in bruxism, and achieved by other types of resins.

\section{CONCLUSION}

- Impak resin used for manufacturing nightguards mitigated the effects of stress and reduced both the bruxism and the painful symptoms in cranio-mandibular area;

- The mechanical strength of slow heat-cured nightguards was better than those of fast-cured ones;

- The colour shade stability of slower-treated nightguards was better than of fast-cured ones;

- Respecting of proper technology of Impak resin is paramount in obtaining nightguards with good mechanical and optical properties

\section{REFERENCES}

Bumann A., Lotzmann U., Mah J. (2002). TMJ Disorders and Orofacial Pain-The Role of Dentistry in a Multidisciplinary Diagnostic Approach, Thieme Publishing Group, StuttgartNew York, ISBN-10: 1588901114, ISBN-13: 9781588901118

Gebelein C.G. (Rapra Technology Limited, 1991). Biomedical Applications of Polymers, Issue 51 of Review Reports, Volume 5, Issue 3 of Rapra review reports, Elsevier Publisher, Shawbury, Shrewsbury, Shropshire, UK, ISBN 0080417469,9780080417462

Shalaby S.W. (2006). Polymers for Dental and Orthopedic Applications (Advances in Polymeric Biomaterials), CRC Press Publisher, Boca Raton, Fl. United States, 1st edition ISBN: 0849315301

Gerrig R.J., Zimbardo P.G. (2009). Psychology and Life, 19 edition, Allyn \& Bacon Publisher, Needham Heights, Massachusetts, United States, ISBN-10: 0205685919, ISBN-13: 9780205685912

Falace D.A. (2007). Current Clinical Practice: Primary Care Sleep Medicine, Humana Press Inc, Totowa, NJ, ISBN-10: 1588299929; ISBN-13: 9781588299925

Wright E.F. (2010). Manual of Temporomandibular Disorders, second edition, Wiley-Blackwell Publisher, Ames, Iowa, USA, ISBN-10: 0813813247

Naikmasur V, Bhargava P, Guttal K, Burde K. (2008). Soft nightguard therapy in the management of myofascial pain dysfunction syndrome: a follow-up study. Indian J Dent Res., Medknow Publications, 19(3):196-203, ISSN: 09709290, PMID: 18797094 